\title{
Posterior Pelvic Ring Fractures: Closed Reduction and Percutaneous CT-Guided Sacroiliac Screw Fixation
}

\author{
Augustinus Ludwig Jacob, ${ }^{1}$ Peter Messmer, ${ }^{2}$ Klaus-Wilhelm Stock, ${ }^{1}$ Norbert Suhm, ${ }^{2}$ Bernard Baumann, ${ }^{1}$ \\ Pietro Regazzoni, ${ }^{2}$ Wolfgang Steinbrich ${ }^{1}$ \\ 'Institute of Diagnostic Radiology, Kantonsspital-Universitätskliniken, CH-4031 Basel, Switzerland \\ ${ }^{2}$ Department of Surgery, Kantonsspital-Universitätskliniken, CH-4031 Basel, Switzerland
}

\begin{abstract}
Purpose: To assess the midterm results of closed reduction and percutaneous fixation (CRPF) with computed tomography (CT)-guided sacroiliac screw fixation in longitudinal posterior pelvic ring fractures. To document radiographic and CT follow-up patterns. Methods: Thirteen patients with 15 fractures were treated. Eleven patients received a unilateral, two a bilateral, screw fixation. Twenty-seven screws were implanted. Continuous on-table traction was used in six cases. Mean radiological follow-up was 13 months.

Results: Twenty-five (93\%) screws were placed correctly. There was no impingement of screws on neurovascular structures. Union occurred in $12(80 \%)$, delayed union in $2(13 \%)$, and nonunion in 1 of $15(7 \%)$ fractures. There was one screw breakage and two axial dislocations.

Conclusion: Sacroiliac CRPF of longitudinal fractures of the posterior pelvic ring is technically simple, minimally invasive, well localized, and stable. It should be done by an interventional/surgical team. CT is an excellent guiding modality. Closed reduction may be a problem and succeeds best when performed as early as possible.
\end{abstract}

Key words: Pelvis, fractures-Interventional procedures - Computed tomography guidance-Closed reduction and percutaneous fixation (CRPF)

Open reduction and internal fixation (ORIF) is considered the treatment of choice in vertically unstable longitudinal fractures of the posterior pelvic ring. Exsanguination, sepsis, and multiorgan failure, as well

Correspondence to: Dr. A.L. Jacob as disabling chronic pain and functional deficits, can thus be partially avoided [ $1-4]$. Furthermore, malunion and nonunion in up to $54 \%$ of cases have been described with conservative treatment [4]. Drawbacks to ORIF are considerable tissue traumatization, substantial intraoperative blood loss, and up to $25 \%$ infectious complications $[5,6]$. Closed reduction and percutaneous fixation (CRPF) combines the advantages of ORIF with those of conservative therapy by taking a minimally invasive approach to screw insertion. It is a valid alternative to ORIF in these fractures, provided they can be externally reduced. Sacroiliac CT-guided CRPF was first described in 1987 and 1992 by Ebraheim et al. $[5,7]$ and subsequently reported by Nelson and Duwelius [8] and Duwelius et al. [9].

We report 15 longitudinal sacroiliac fractures and fracture dislocations. Two sacroiliac screws per side were inserted routinely and, in fractures with cephalad displacement, continuous on-table traction was maintained. Primary screw placement, reduction of the fracture gap and of dislocations, as well as osseous union or nonunion, were assessed with a systematic radiological midterm follow-up consisting of computed tomography $(\mathrm{CT})$ and erect plain films of the pelvis.

\section{Materials and Methods}

\section{Patients and Fractures (Table 1)}

Four female and 9 male patients with 15 combined anterior and vertically unstable longitudinal posterior pelvic ring fractures and a mean age of 41 years (range 18-66 years) were treated between April 1993 and May 1995. Ten patients $(77 \%)$ treated were polytraumatized: traumatic lesions included peripheral and central neurological injuries, a variety of fractures, rupture of urinary bladder and bowel, hematothorax, and severe bleeding. In two patients, a manifest source of bleeding was treated by embolization of the internal iliac artery 
Table 1. Patients and fractures

\begin{tabular}{|c|c|c|c|c|c|c|c|c|c|c|}
\hline $\begin{array}{l}\text { Patient } \\
\text { no. }\end{array}$ & Sex & $\begin{array}{l}\text { Age } \\
(\mathrm{yr})\end{array}$ & Injury & Polytrauma & $\begin{array}{l}\text { Affected } \\
\text { side }\end{array}$ & Classification (Tile) & $\begin{array}{l}\text { Zone } \\
\text { (Denis) }\end{array}$ & $\begin{array}{l}\text { Delay to } \\
\text { operation } \\
\text { (days) }\end{array}$ & $\begin{array}{l}\text { Total hospital } \\
\text { stay (days) }\end{array}$ & $\begin{array}{l}\text { Postoperative } \\
\text { hospital stay } \\
\text { (days) }\end{array}$ \\
\hline 1 & M & 18.1 & $\begin{array}{l}\text { Motorbike } \\
\text { accident }\end{array}$ & Yes & $\mathbf{L}$ & $\mathrm{C} 1.3$ & $2-3$ & 7 & 9 & 2 \\
\hline 2 & $\mathbf{M}$ & 20.1 & $\begin{array}{l}\text { Crush } \\
\text { under fork- } \\
\text { lift truck }\end{array}$ & No & Bilateral & C3 (C1.2 R, C1.3 L) & $1 \mathrm{R}, 3 \mathrm{~L}$ & 15 & 62 & 54 \\
\hline 3 & $\mathrm{~F}$ & 21.5 & $\begin{array}{l}\text { Motor } \\
\text { vehicle } \\
\text { accident }\end{array}$ & Yes & $\mathbf{L}$ & $\mathrm{C} 1.3$ & 2 & 2 & 24 & 22 \\
\hline 4 & $\mathbf{M}$ & 20.6 & $\begin{array}{l}\text { Crush } \\
\text { under car } \\
\text { falling } \\
\text { from jack }\end{array}$ & No & $\mathbf{L}$ & $\mathrm{C} 1.2$ & 1 & 12 & 48 & 36 \\
\hline 5 & M & 53.6 & $\begin{array}{l}\text { Fall from } \\
2.5 \mathrm{~m}\end{array}$ & No & $\mathbf{L}$ & $\mathrm{C} 1.3$ & 2 & 9 & 73 & 64 \\
\hline 6 & M & 61.3 & $\begin{array}{l}\text { Somersault } \\
\text { from } \\
\text { bicycle }\end{array}$ & Yes (initially) & $\mathbf{R}$ & $\mathrm{C} 1.3$ & 2 & 213 & 225 & 12 \\
\hline 7 & M & 52.9 & $\begin{array}{l}\text { Crush } \\
\text { under } \\
\text { falling } \\
\text { excavator }\end{array}$ & Yes & $\mathbf{R}$ & $\mathrm{C} 1.2$ & 1 & 5 & 83 & 78 \\
\hline 8 & $\mathrm{~F}$ & 66.6 & $\begin{array}{l}\text { Fall from } \\
\text { window }\end{array}$ & Yes & $\mathbf{L}$ & $\mathrm{C} 1.3$ & 2 & 8 & 16 & 8 \\
\hline 9 & $\mathrm{~F}$ & 44.9 & $\begin{array}{l}\text { Fall from } \\
\text { first floor }\end{array}$ & Yes & $\mathbf{R}$ & $\mathrm{C} 1.3$ & 2 & 26 & 35 & 9 \\
\hline 10 & M & 50.2 & $\begin{array}{l}\text { Fall from } \\
\text { balcony }\end{array}$ & Yes & $\mathbf{L}$ & $\mathrm{C} 1.3$ & 2 & 14 & 47 & 33 \\
\hline 11 & $\mathbf{M}$ & 41.3 & $\begin{array}{l}\text { Stunt } \\
\text { chute } \\
\text { accident }\end{array}$ & Yes & $\mathbf{L}$ & $\mathrm{C} 1.3$ & 2 & 8 & 31 & 27 \\
\hline 12 & M & 43.9 & $\begin{array}{l}\text { Motor } \\
\text { vehicle } \\
\text { accident }\end{array}$ & Yes & Bilateral & $\mathrm{C} 3(\mathrm{C} 1.3 \mathrm{R}, \mathrm{C} 1.3 \mathrm{~L})$ & $2 \mathrm{R}, 2 \mathrm{~L}$ & 18 & 40 & 22 \\
\hline 13 & $\mathrm{~F}$ & 37.9 & $\begin{array}{l}\text { Fall from } \\
9 \mathrm{~m}\end{array}$ & Yes & L & C1.2 & 1 & 3 & 95 & 92 \\
\hline Mean & & 41.0 & & & & & & 26.2 & 60.6 & 35.3 \\
\hline Median & & 43.9 & & & & & & 9.0 & 47.5 & 27.0 \\
\hline
\end{tabular}

$\mathrm{L}=$ left side; $\mathrm{R}=$ right side

and surgical repair of an arterial mesenteric branch, respectively. Two additional patients received mass transfusions for treatment of diffuse bleeding. The sequence of treatment depended on the respective severity of injuries, was discussed between specialties involved, and was decided upon by the trauma surgeon in charge of the patient. A median delay from trauma to screw fixation of 9 days (range 2-213 days) resulted. For better reduction we now try to do screw fixation in the first $48 \mathrm{hr}$ after initial stabilization. Median postoperative hospital stay was 27 days (range 2-92 days).

Sacroiliac fractures and dislocations were classified according to Tile [3]. Additionally the zone, according to Denis et al. [10], was noted. They define three longitudinal zones of the sacrum: zone 1 comprises the sacral ala up to, but not including, the foramina; zone 2 includes the foramina; and zone 3 the neural canal. If the sacrum was not affected, the fracture was classified as a zone 1 lesion.

\section{Operative Technique}

The operative technique differed from descriptions in the literature [5, 7-9]. It employed the use of two sacroiliac screws instead of one and one posterior biiliac screw because this immobilizes the initially unaffected contralateral sacroiliac joint also. Two means of fixation are needed to block rotation of fragments. Additionally, we used continuous intraoperative, on-table traction with $4-8 \mathrm{~kg}$ in the 6 of $15(40 \%)$ fractures with cephalad displacement. It was maintained using an extension taped to the patient's affected leg. The cord connecting extension and weight ran over a wall-mounted roll. With weights above $5 \mathrm{~kg}$, the outward, pulling motion of the CT table had to be assisted by manually lifting the weight to assure good reproduction of scanning levels. To prevent sliding, the patient was taped to the vacuum mattress and the mattress in turn to the CT table.

All operations were performed with the patient under general anesthesia and with antibiotic prophylaxis. All patients received low molecular weight heparin perioperatively. The procedures were done in the CT suite using a Somatom DRH Scanner (Siemens, Erlangen, Germany) with a $512 \times 512$ matrix. All patients were placed feet first and immobilized with a vacuum mattress. All except three lay in the lateral decubitus position; the first two were placed in a prone position according to the literature [5, 7-9]. One patient was placed in a supine position because of gross dislocation of the symphysis pubis in the lateral position. Disinfection and draping were done by trained scrub nurses. Sterile measures were approved by the hygiene commission of the hospital. The team consisted of an interventional 
Table 2. Displacement and reduction

\begin{tabular}{|c|c|c|c|c|c|c|c|}
\hline \multirow[t]{3}{*}{ Case no. } & \multirow[t]{3}{*}{ Fracture } & \multicolumn{4}{|c|}{ Displacement (mm) } & \multicolumn{2}{|c|}{ Fracture gap (mm) } \\
\hline & & \multicolumn{2}{|l|}{ Craniocaudal } & \multicolumn{2}{|l|}{ Dorsoventral } & \multirow[t]{2}{*}{ Preoperative } & \multirow[t]{2}{*}{ Postoperative } \\
\hline & & Preoperative & Postoperative & Preoperative & Postoperative & & \\
\hline 1 & 1 & 5.0 & 5.0 & 0.0 & 0.0 & 5.0 & 0.0 \\
\hline 2 & $2(\mathrm{R})$ & 15.0 & 21.0 & 0.0 & 0.0 & 20.0 & 3.0 \\
\hline 2 & 3 (L) & 0.0 & 0.0 & 0.0 & 0.0 & 5.0 & 1.0 \\
\hline 3 & 4 & 39.0 & 14.0 & 35.0 & 3.0 & 10.0 & 3.0 \\
\hline 4 & 5 & 10.0 & 8.0 & 0.0 & 0.0 & 12.0 & 0.0 \\
\hline 5 & 6 & 5.0 & 5.0 & 0.0 & 0.0 & 12.0 & 10.0 \\
\hline 6 & 7 & 20.0 & 17.0 & 10.0 & 10.0 & 12.0 & 10.0 \\
\hline 7 & 8 & 0.0 & 0.0 & 0.0 & 0.0 & 8.0 & 2.0 \\
\hline 8 & 9 & 0.0 & 0.0 & 0.0 & 0.0 & 15.0 & 10.0 \\
\hline 10 & 9 & 4.0 & 4.0 & 0.0 & 0.0 & 3.0 & 0.0 \\
\hline 10 & 11 & 0.0 & 0.0 & 10.0 & 10.0 & 10.0 & 0.0 \\
\hline 11 & 12 & 10.0 & 14.0 & 0.0 & 0.0 & 10.0 & 0.0 \\
\hline 12 & $13(\mathrm{R})$ & 0.0 & 0.0 & 0.0 & 0.0 & 3.0 & 0.0 \\
\hline 12 & $14(\mathrm{~L})$ & 0.0 & 0.0 & 0.0 & 0.0 & 3.0 & 0.0 \\
\hline 13 & 15 & 21.0 & 0.0 & 20.0 & 0.0 & 10.0 & 0.0 \\
\hline \multirow{4}{*}{\multicolumn{2}{|c|}{$\begin{array}{l}\text { Mean } \\
\text { Difference } \\
p \text { (two-sided } t \text {-test } \\
\quad \text { for paired } \\
\quad \text { samples) }\end{array}$}} & 8.6 & 5.9 & 3.7 & 1.5 & 9.2 & 2.7 \\
\hline & & & 3.7 & & 2.2 & & 6.5 \\
\hline & & & & & & & \\
\hline & & & NS & & NS & & $<0.0001$ \\
\hline
\end{tabular}

$\mathrm{R}=$ right side; $\mathrm{L}=$ left side; $\mathrm{NS}=$ not significant

radiologist and a trauma surgeon experienced in internal pelvic fixation.

The basic technique of $\mathrm{CT}$-guided sacroiliac screw fixation has been described $[5,8]$ and closely resembles standard CT-guided biopsy techniques. If a diagnostic CT examination had already been done, only the region of interest was rescanned; otherwise a formal pelvic CT examination was performed. With spiral CT we now do 2-dimensional and 3-dimensional pelvic reconstructions in cases of longitudinal displacement to assess reduction. Screw placement is as follows: Two screws are inserted into S1. If this is not possible due to limited volume, the second screw is inserted into S2. If bilateral fixation is to be performed, at least one screw on each side is placed in S1. The screws cross the fracture line as close to a right angle as possible and must not impinge on the sacral foramina or canal. Sevenmillimeter cannulated screws with washer (Association for the Study of Internal Fixation, ASIF) were used throughout.

Marking, initial guide pin placement, guide pin and gliding hole drilling, screw placement, and controls were always done in tandem for both screw locations to speed up the procedure. S1 screws typically were $0.8-1.6 \mathrm{~cm}$ apart.

Surgery was performed between 2 days and 7 months (median 9 days) after trauma. Median duration of surgery was $86 \mathrm{~min}$. Approximately $90 \%$ of this time is spent in planning, placement, and preparation, $10 \%$ in performance. Imaging time may constitute $10 \%$ of total time. Median anesthetic time was $190 \mathrm{~min}$ including transport from and to the intensive care unit in intubated patients, placement in all patients, and eventually intubation on the CT table. Room times are slightly shorter than anesthetic times but were not recorded.

\section{Radiological Documentation}

Preoperative radiological documentation included anteroposterior plain films of the pelvis and a pelvic CT scan. Spiral CT was not then available at our institution but is in use now for these cases. Inlet and outlet views were done only occasionally. Radiological follow-up consisted of routine control images and a prospective reevaluation with CT and erect plain films of the pelvis between April 11, 1995 and October 20, 1995. Reading of the films was done and measurements were taken by an experienced radiologist (A.L.J.). Mean follow-up was 13 months.

Pre- and postoperative documents were compared and evaluated for the following criteria: sacroiliac fracture pattern and fracture gap width, other pelvic fractures, sacroiliac widening, craniocaudal and dorsoventral displacement of the lateral pelvic fragment, possible involvement of sacral foramina and sacral canal, fracture reduction, implant position, and osseous union or nonunion.

Dorsoventral displacement and width of fracture gap were taken from the CT films. Displacement was measured from cortex to cortex, fracture gap as the widest distance between fragments perpendicular to the fracture line. A fracture gap was called closed if there was contact of the fragments over most of the length. Presurgical and postsurgical cephalad displacement was measured on the plain pelvic films with the contralateral side as the reference. A screw was called "well positioned" if it was placed nearly perpendicular to the fracture line, if it did not impinge on neural structures, if it assumed as central a position as possible given the other constraints, if the thread was completely in the distant fragment and the longest possible thread was used, and if the fracture gap was closed by securing the screw. An osseous union was diagnosed on the CT scans if the fracture gap was solidly bridged over most of its length by callus or cancellous bone in primary healing. Partial and fragile bridging of the fracture gap was called a delayed union, whereas in nonunion, the fracture gap was completely open.

\section{Results}

\section{Primary Screw Positioning}

Twenty-seven screws were inserted. Twenty-five of 27 (93\%) screws were judged to be well positioned. One screw was deemed too short and too far ventrally. In 

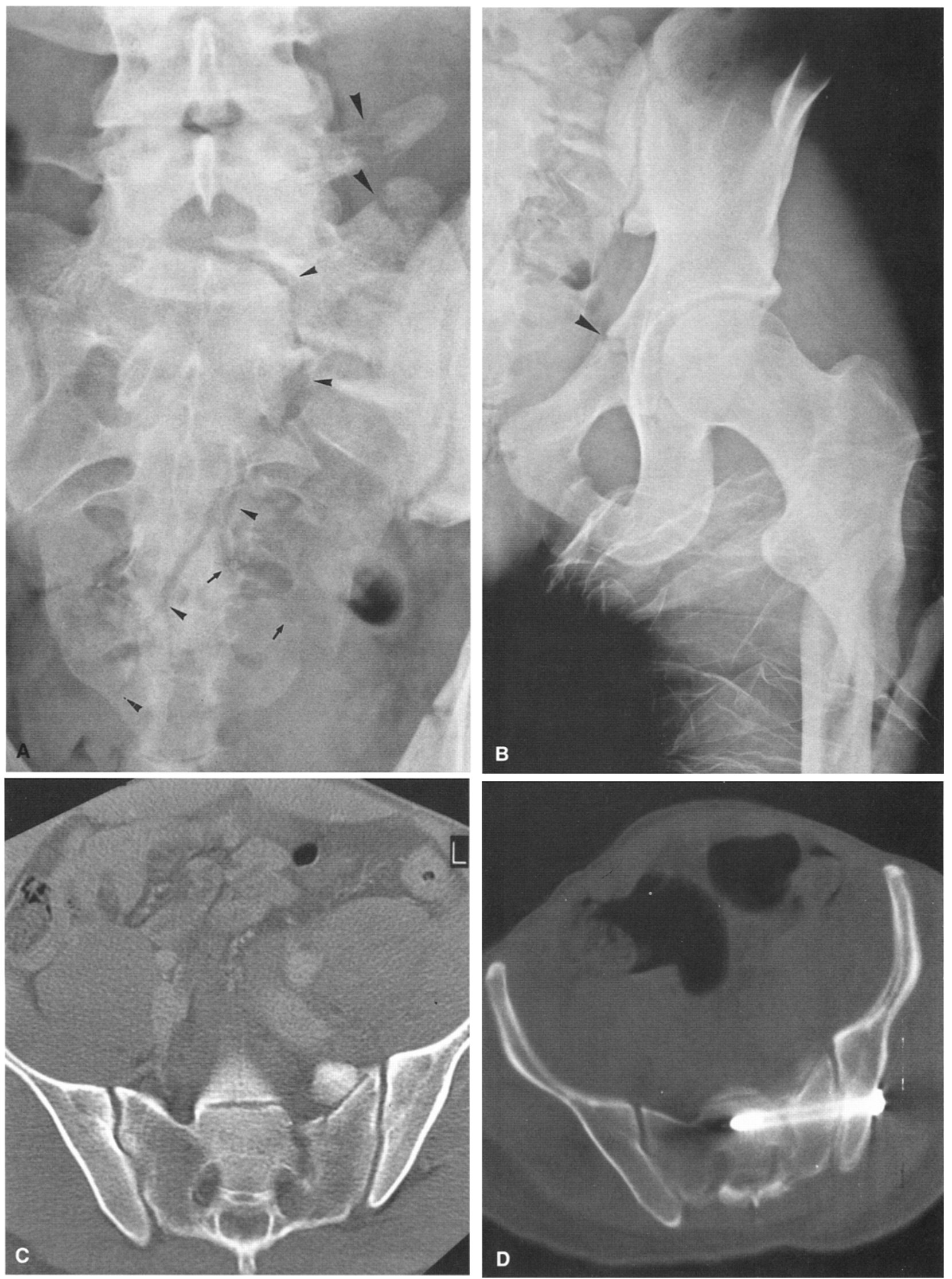

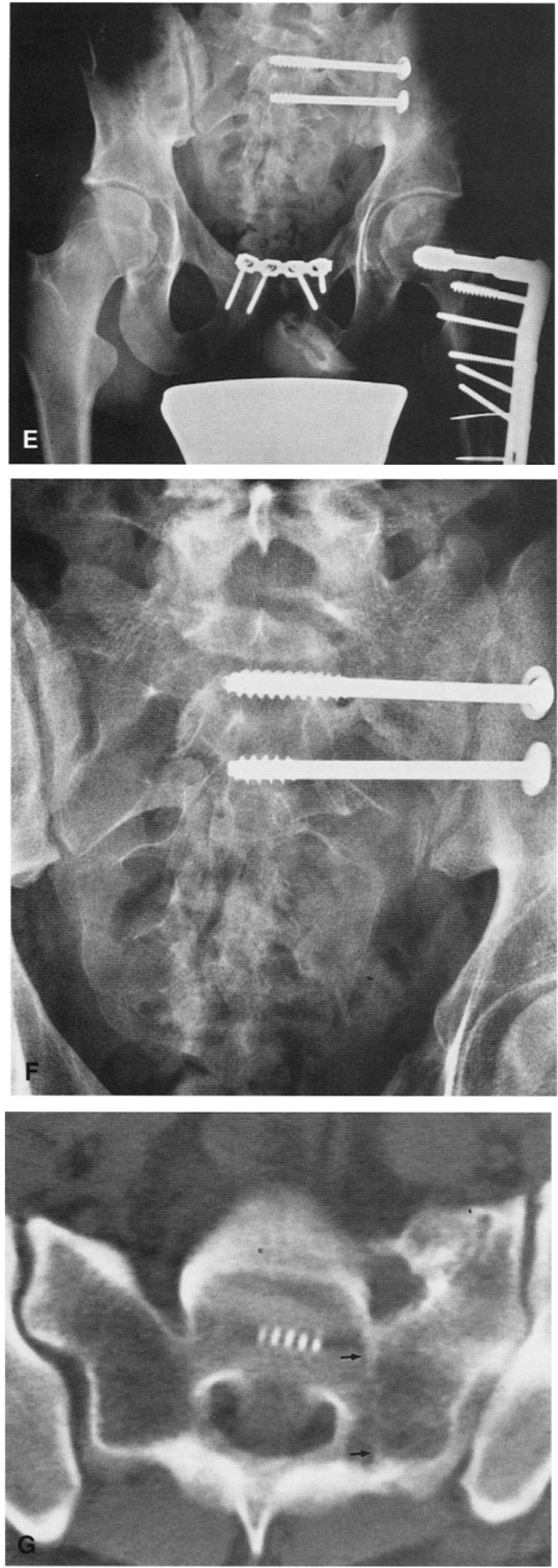

another patient the fracture gap could not be closed. In no case did a screw impinge on a sacral nerve root.

\section{Fracture Gap and Displacement (Table 2)}

In all cases the fracture gap width decreased from trauma to last follow-up. There were three fractures with a substantial residual gap of $10-\mathrm{mm}$ width and four fractures with a dorsoventral dislocation $>0$ $\mathrm{mm}$. In two cases the dislocation remained unchanged from trauma to last follow-up and in two a substantial reduction (from 35 to $3 \mathrm{~mm}$ and from 20 to $0 \mathrm{~mm}$, respectively) was achieved. Presurgical and postsurgical dorsoventral displacement showed no statistically significant difference, whereas the respective fracture gap width difference was highly significant $(p<0.0001)$.

Pre- and postsurgical cephalad displacement showed no statistically significant difference; there were nine fractures with a measurable cephalad displacement. In two the dislocation increased from trauma to last follow-up, in three there was no difference, and in four the dislocation diminished. There were two fractures where a substantial reduction (from 39 to $14 \mathrm{~mm}$ and from 21 to $0 \mathrm{~mm}$, respectively) was achieved. Both fractures were reduced within $24 \mathrm{hr}$. When classified according to Nelson and Duwelius [8], the postreduction position of 10 of 15 fractures was

Fig. 1. Example of primary osseous union (case 1). Motorbike accident in an 18-year-old man. Vertically unstable but nondisplaced fracture C1.3 according to Tile [3] and zone 3 according to Denis [10]. Transient cauda syndrome. Successful sacroiliac closed reduction with percutaneous fixation (CRPF) with uneventful recovery. Detail of the plain pelvic antero-posterior view at the time of trauma (A) demonstrates the curved main fracture line affecting the left sacral foramina and crossing the sacral canal at the level of S4, ultimately reaching the contralateral cortex (small arrowheads). There is another fracture separating the left caudal part of the sacrum together with the coccyx from the dorsal pelvic ring (arrows). Avulsion fractures of the transverse process of L5 and of the left upper corner of the lateral mass of the sacrum indicate rupture of iliolumbar and lateral lumbosacral ligaments (large arrowheads). B There is a rupture of the symphysis pubis, a fracture of the left lower pubic ramus, a nondisplaced left acetabular fracture (arrowhead), and a subtrochanteric left femoral fracture. C Initial CT scan at the level of S2 reveals more clearly some ventral comminution and involvement of the foramina. D Intraoperative $C T$ scan shows the sacroiliac screw at the level of S2. The fracture gap has been closed. E Follow-up erect pelvic film at 9.2 months (detail in F) shows that the main fracture line has closed in its middle section). Symphysis had been reduced and internally fixed with a reconstruction plate. Other fractures mentioned have all healed with minimal displacement, the femoral fracture after open reduction and internal fixation. G Follow-up CT demonstrates osseous union of the fracture and bony bridging of pelvic opening of first left sacral foramen. Increased density along the former fracture line corresponds to callus formation (arrows). There is no noticeable movement of fixation screws. The patient is pain free and back at work. 
excellent ( $\leq 5-\mathrm{mm}$ dislocation), 1 good (between 5and $10-\mathrm{mm}$ dislocation) and 2 fair $(10-15 \mathrm{~mm})$. In two cases the residual cephalad displacement was greater than $15 \mathrm{~mm}$, namely, 17 and $21 \mathrm{~mm}$, respectively.

\section{Osseous Union}

At the last follow-up there was a complete union in 12 of 15 fractures (Fig. 1). At the last follow-up there was a complete union in 12 of 15 fractures (Fig. 1). There were two delayed unions (Fig. 2) and one nonunion with hypotrophic pseudo-arthrosis (Fig. 3).

\section{Subjective Clinical Assessment}

Ten of 13 patients (77\%) judged the postoperative result as being excellent or good, 1 as fair, and 2 as bad. The physicians doing the last follow-up examination rated the results as excellent or good in $11(85 \%)$ and fair or bad in $2(15 \%)$ cases. The single differing rating was in the case of a morbidly obese female patient (case 8) who also suffered from a schizoaffective psychosis. At last follow-up, 10 patients (77\%) reported no, only slight, or exercise-dependent pain. Three patients (23\%) still complained of severe pain, one of whom had a primary unsatisfactory reduction, one a screw loosening, and one a good radiological result.

\section{Neurological and Urogenital Symptoms}

Of the four fractures affecting zone 1, a slight residual power deficit was seen in only one (25\%). In 9 of 11 fractures (82\%) affecting zones 2 and 3 there were neurological symptoms. Nine patients had traumatic neurological symptoms. In only one of them did a traumatic L5 lesion temporarily deteriorate after surgery.

\section{Gait and Hip Joint Motion Range}

At last follow-up all patients were able to walk. Five (39\%) needed one or two crutches, and eight $(61 \%)$ needed no stick. Hip joint motion was generally satisfactory on the affected side.

\section{Implant-Related Complications}

In the two bilateral procedures, only a single screw was placed on one side. In one case the screw was broken at last follow-up and the fracture had started to heal. The other nondisplaced fracture healed without implant-related problems. In a morbidly obese and osteoporotic female patient (case 8) the instruments were too short and therefore a second screw was not attempted. The fracture gap could not be closed and the screw, which had only a $16-\mathrm{mm}$ thread, eventually dislocated axially. She additionally had an ORIF of the symphysis pubis whereas the other two patients only had the sacroiliac screw fixation. Thus, in two of three fractures fixed with only one screw, implant-related problems occurred. There was one further screw loosening during primary hospitalization; it was refixed through a stab incision.

\section{Other Complications}

One patient experienced a superficial wound infection which healed without sequelae. Four systemic complications were considered consequences of multiple injury rather than CRPF. One patient suffered a central pulmonary embolism and was treated with anticoagulants; he eventually recovered. One case of pneumonia and two of necrotizing cholecystitis, one of them 5 months after CRPF, were successfully treated with antibiotics and surgery, respectively. There was no associated mortality.

\section{Discussion}

\section{Placement}

In the literature, placement of patients in CT-guided procedures was mostly prone [5, 7-9]. In this position there is some outward force acting on both iliac wings, which may lead to increased diastasis of the fracture. The contralateral decubitus position normally employed in our series tends to spontaneously reduce the fracture gap.

\section{Closed Reduction and Continuous Traction}

Contrary to the literature, we had problems with reaching closed reduction before and maintaining and supervising it during the procedure, even though we routinely used continuous on-table traction. Only two of the dislocated fractures (cases 3 and 13) could be substantially reduced, both in the first $24 \mathrm{hr}$. In all other cases we were either unable to reach a noticeable improvement of fragment position or we did not intend reduction in the first place because of minor initial dislocations.

In our opinion reaching and supervising closed longitudinal reduction is a problem still to be solved. The digital radiography projections are mostly far from true lateral or antero-posterior views and are difficult to read. The axial slices do little to solve this problem since there is no perfect parallelity of the long axes of patient and table. Multiplanar or 3-dimensional reconstructions require thin axial slicing which adds to the radiation dose 

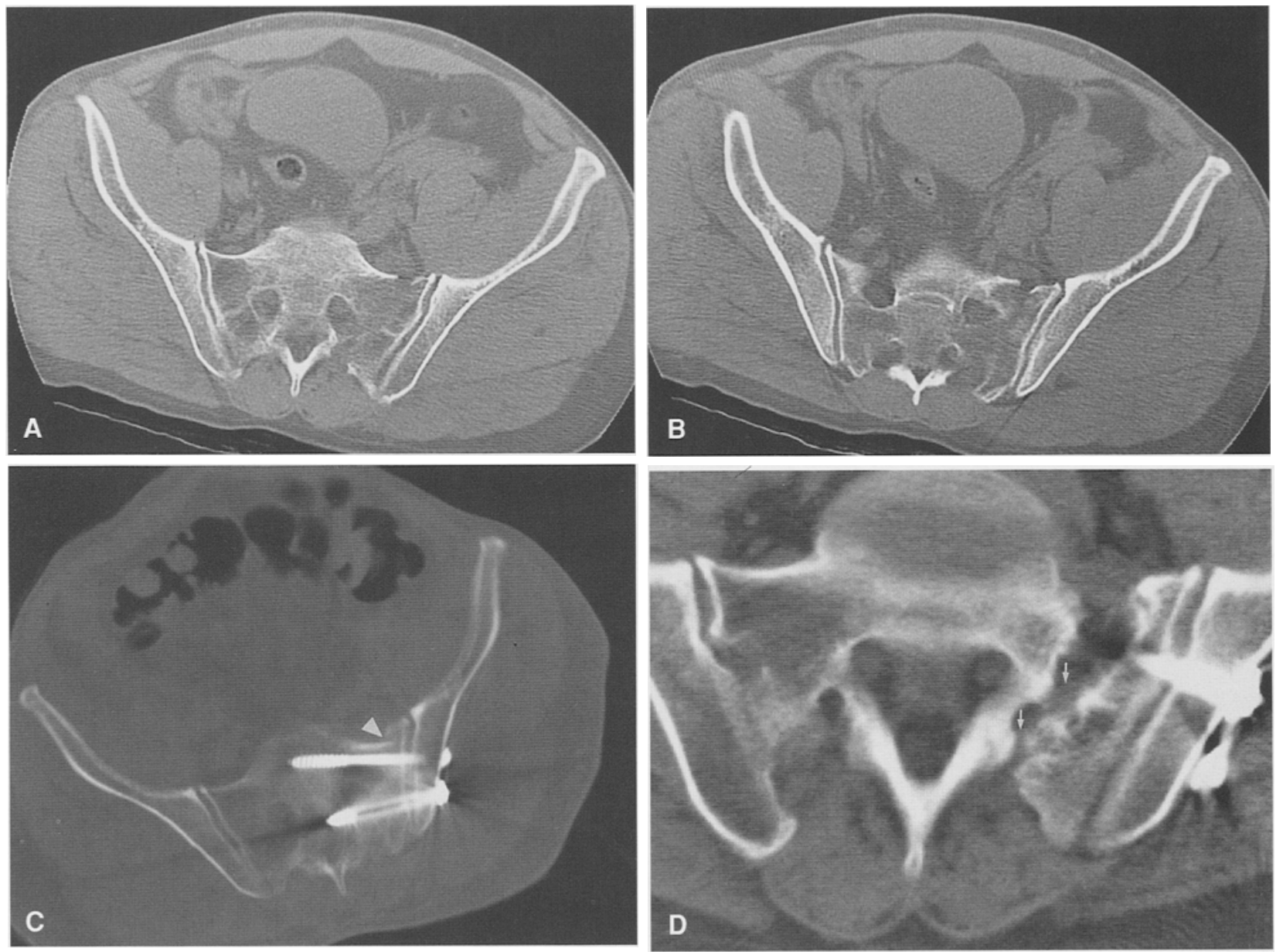

Fig. 2. Example of delayed osseous union (case 5). A 54-year-old man fell from a height of $2.5 \mathrm{~m}$ in an occupational accident. A Tile C1.3 fracture of left sacrum with progressive deficit of left L5 nerve root function was diagnosed. After sacroiliac CRPF, this progressive deficit continued to deteriorate and ultimately necessitated neurosurgical decompression by left L5 hemilaminectomy. Afterwards, function clearly improved. Early axial dislocation of the S2 screw necessitated refixing. Additionally, the patient suffered from paracentra pulmonary embolism which was successfully treated by heparinization. Initial radiographic investigation reveals a vertically unstable Tile C1.3 fracture of left sacrum with avulsion of left L5 transverse process as well as fractures of the right pubic and sciatic bones. Pelvic

CT at the level of $\mathrm{S} 1$ and $\mathbf{S} 2$ demonstrates diastasis of about $10 \mathrm{~mm}$ and distinct osteoporosis (A, B). Injury affects zone 2 according to Denis. C Intraoperative scan shows correct positioning of both S1 and S2 screws. Note the extremely precise positioning of the S2 screw between the sacral foramen ventrally and the sacral canal dorsally. The fracture gap has been closed as indicated by ventral overlap of the lateral fragment (white arrowhead). D Six and a half months later CT demonstrates marked resorption of fragment margins with some bony bridges crossing the fracture gap (white arrows) corresponding to delayed union. The patient was unable to work, complained of severe pain, and needed two walking sticks at last clinical follow-up.

and is slow in dynamic situations of repeated reduction and control. In several cases we additionally used C-arm fluoroscopy, but since the CT table support is very close to the gantry, the handling is awkward. Dorsoventral dislocation and reduction, however, is easily seen on CT slices.

\section{Guiding Modality}

Even recent publications report the use of fluoroscopic guidance $[4,11,12]$. Routt et al. [12] describe the technique and its limits in great detail and give examples of

misplaced screws. They note that preoperative instructions to the radiology technician "may save hours of unnecessary exposures." Obviously the guiding modality is part of the problem here. CT guidance provides a solution, where direct in-plane sight of the screw path dependably prevents misplacement. On the negative side, a CT suite is not normally adapted for open bone surgery. This may make it necessary to choose a staged approach in cases requiring open reduction or other open surgery.

\section{Implants and Osseous Union}

We saw implant problems in two of three screws in single-screw fixation. Of these, case 8 , the morbidly 

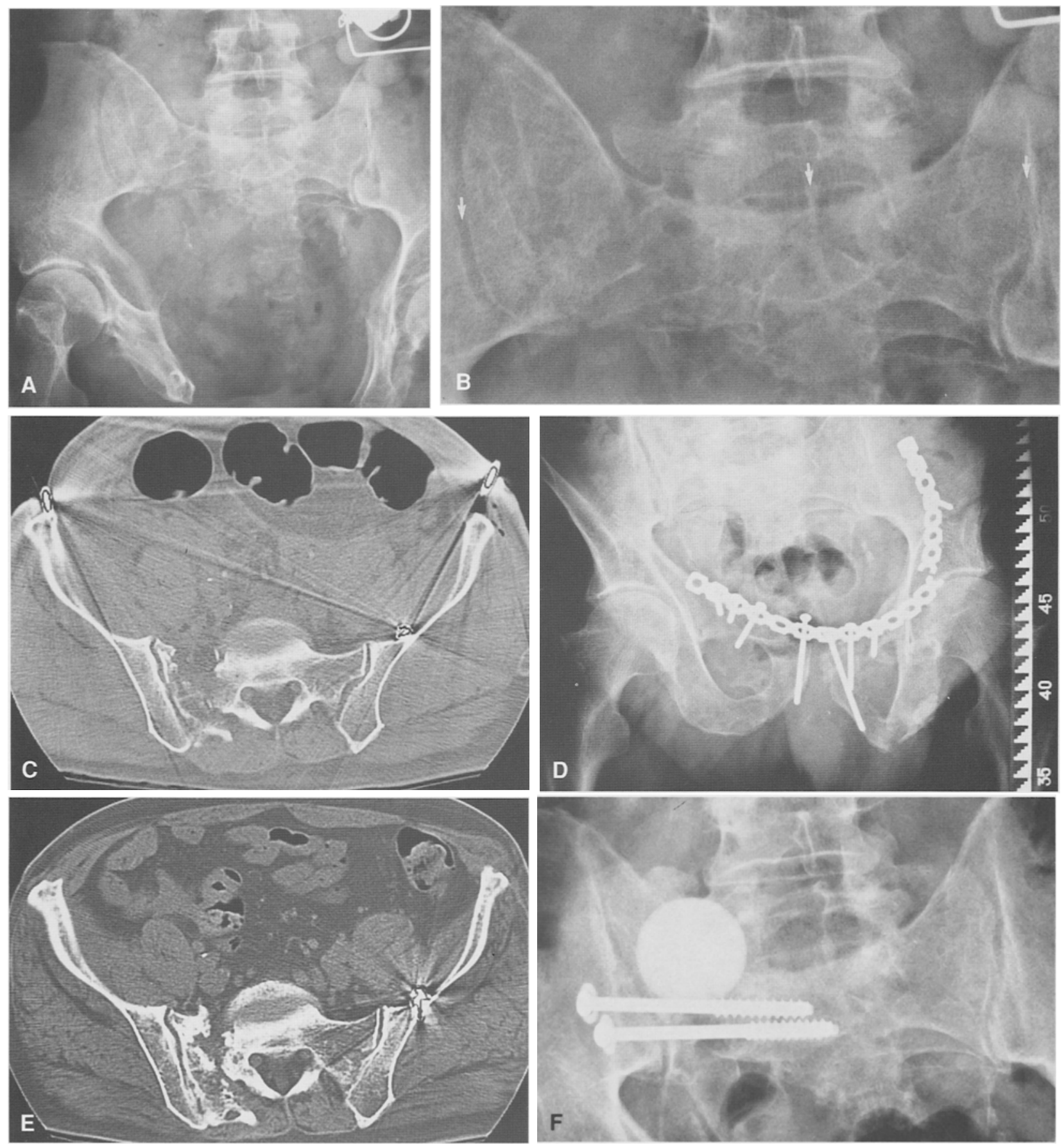

Fig. 3. Example of osseous nonunion (case 6). A 61-year-old man somersaulted from a bicycle and was admitted with a comminuted and displaced Tile C1.3 fracture. A Trauma plain pelvic radiograph demonstrates important external rotation of the right hemipelvis leading to marked symphyseal diastasis and a comminuted fracture of the right sacral mass probably involving zone 2 . Distance from the right sacroiliac joint to the midline, as defined by sacral spinous processes, is clearly wider than on the contralateral side $(\mathbf{B}$, detail of $\mathbf{A}$; white arrows). This implies a substantial fracture gap of around $10-20 \mathrm{~mm}$. The sacroiliac joint proper seems to be unaffected on both sides. There is approximately $20 \mathrm{~mm}$ of right cephalad displacement as well as a slightly dislocated acetabular fracture and os pubis fracture on

the right. C CT confirms the findings. The patient was treated with anterior ORIF by means of an ASIF reconstruction plate. D Plain pelvic antero-posterior view 6 months after initial trauma detects breakdown of the reconstruction plate. E CT shows resorption, smoothing, and sclerosis of fragment margins. Technically successful sacroiliac screw fixation was performed to prevent impending pseudo-arthrosis. Osseous union did not occur. F At last follow-up the fracture gap is still visible with marginal scletosis. Note the hyperlucent band around the tip of both screws, indicating loosening. The patient complained of continuing pain and was unable to return to work. 
obese patient, was a primary technical failure. Conversely, there were implant problems in only 1 of 24 screws placed in the double-screw technique (case 5). This tendency was also noted by Nelson and Duwelius [8]. The latter screw was placed into a comminuted area and could not be secured fully. Both cases resulted in delayed union. There was only one nonunion, in a case of preexistent pseudo-arthrosis fixed secondarily after 213 days (case 6).

In purely sacral fractures, sacroiliac screw fixation produces an unnecessary arthrodesis of the sacroiliac joint. This has been criticized in the literature $[13,14]$, although there are no known clinical disadvantages.

\section{Traumatic Neurological Injury}

The percentage of neurological injuries has been as high as 50\% [15]. In our series, 9 of $13(69 \%)$ patients showed neurological symptoms. The probability of neural compromise sharply rises the closer the fracture is to the sacral midline [10]. In our patients, $25 \%$ of fractures in zone 1 according to Denis and Davis [10] produced symptoms, compared with $82 \%$ of fractures in zones 2 and 3.

\section{Iatrogenic Neurological Injury}

Iatrogenic neurovascular injury can appear during reduction and fixation. Direct injury is caused by contact of surgical instruments with neural structures. Indirect injury arises from compression or distraction of neural structures through reducing and fixing the bony fragments.

Direct injury has not been observed by us or others who used direct visual control by CT guidance. Somatosensory-evoked potentials (SSEPs) have been proposed as an indirect control [16]. They are not positive before the instrument already impinges onto a nerve root and thus do not contribute to positive guidance.

Impending indirect injury is more difficult to predict by imaging techniques. Clues can be detected from the fracture pattern: involvement of the sacral foramina or the sacral canal, substantial residual displacement before osteosynthesis, and preexisting neurological symptoms all are indicators of possible indirect injury by fracture compression during screw fixation. SSEPs could possibly assess an ongoing neural contusion while the sacroiliac screws are tightened [16].

\section{Pain}

The main long-term problem in sacroiliac fractures is persisting pain. According to Tile [3] this is often associated with a primary disruption of the sacroiliac joint and with residual dislocation and instability. Three of our patients $(23 \%)$ complained of persisting severe pain. In our series the average age was 15.5 years $(41.0$ vs 25.5 years) higher than in Duwelius et al.'s series [9], which may have contributed to the less favorable results.

\section{Team Approach}

These interventions should be planned and performed by an interdisciplinary team whose key members are an experienced interventional radiologist and a senior trauma surgeon. The first is expert in imaging and in image-guided targeting and the latter is trained in surgical decision making, internal fixation, and postoperative care for trauma patients. It is in the patients' best interest if they cooperate closely. In our team we plan and perform as equal partners.

\section{Conclusion}

Sacroiliac CRPF of nondisplaced and externally reducible longitudinal fractures of the posterior pelvic ring is technically simple, minimally invasive, well localized, and stable. Reduction of displaced fragments is best done as early as possible. It can be maintained by continuous on-table traction during CRPF. CT guidance is superior to fluoroscopic guidance. Direct iatrogenic neurovascular injury has not been observed. Sacroiliac screws could be positioned well in the vast majority of cases studied.

The probability of traumatic neurological complications depended strongly on the relation of the fracture to the sacral foramina and canal. Indirect compression may possibly have contributed to an already existing and progressive L5 lesion, but was not observed in any of the other cases.

Acknowledgments. This work was funded in part by the Swiss National Science Foundation. Special thanks go to the CT team for their untiring support.

\section{References}

1. Regazzoni P, Harder F, von Hochstetter A, Nidecker A, Allgöwer M (1983) Verschraubung des Iliosakralgelenkes bei instabilen Beckenfrakturen. Helv Chir Acta 50:73-76

2. Pohlemann T, Bosch U, Gänsslen A, Tscherne H (1994) The Hannover experience in management of pelvic fractures. Clin Orthop 305:69-80

3. Tile M (1995) Fractures of the Pelvis and Acetabulum, 2nd ed. Williams and Wilkins, Baltimore

4. Matta JM, Saucedo T (1989) Internal fixation of pelvic ring fractures. Clin Orthop 242:83-97

5. Ebraheim NA, Rusin JJ, Coombs RJ, Jackson WT, Holyday B (1987) Percutaneous computed-tomography-stabilization of pelvic fractures: Preliminary report. J Orthop Trauma 1:197-204 
6. Poigenfürst J, Ender HG, Zadra A (1992) Komplikationen der operativen Versorgung von Beckenfrakturen. Unfallchirurg 95:210-213

7. Ebraheim NA, Coombs R, Rusin JJ, Hoeflinger MJ, Jackson WT (1992) Percutaneous CT-guided stabilization of complex sacroiliac joint disruption with threaded compression bars: Case report. Orthopedics 15:1427-1430

8. Nelson DW, Duwelius PJ (1991) CT-guided fixation of sacral fractures and sacroiliac joint disruptions. Radiology 180:527-532

9. Duwelius PJ, Van Allen M, Bray TJ, Nelson D (1992) Computed tomography-guided fixation of unstable posterior pelvic ring disruptions. J Orthop Trauma 6:420-426

10. Denis F, Davis S, Comfort T (1988) Sacral fractures: An important problem. Retrospective analysis of 236 cases. Clin Orthop 227:67-81

11. Shuler TE, Boone DC, Gruen GS, Peitzmann AB (1995) Percutaneous sacroiliac screw fixation: Early treatment for unstable posterior pelvic ring disruptions. J Trauma 38:453-458
12. Routt MLC, Meier MC, Kregor PJ, Mayo KA (1993) Percutaneous iliosacral screws with the patient supine technique. Operative Techniques Orthop 3:35-45

13. Pohlemann T, Culemann U, Tscherne H (1992) Vergleichende biomechanische Untersuchungen zur internen Stabilisierung der transforaminalen Sakrumfraktur. Orthopäde 21:413-421

14. Käch K, Trentz O (1994) Distraktionsspondylodese des Sakrums bei "Vertical-shear-Läsionen" des Beckens. Unfallchirurg 97:28-38

15. Schied DK, Kellam JF, Tile M (1991) Open reduction and internal fixation of pelvic fractures. (abstract) $\mathbf{J}$ Orthop Trauma $5: 226$

16. Vrahas M, Gordon RG, Mears DC, Krieger D, Sclabassi RJ (1992) Intraoperative somatosensory evoked potential monitoring of pelvic and acetabular fractures. J Orthop Trauma 6:5058 